\title{
Should we estop ourselves as an act of research?
}

Keywords: estoppels, contradictory, assertions, knowledge, camaraderie, stakeholders, stopping

\section{Editorial}

Have you ever heard of the word estoppels? Although somewhat unfamiliar terminology to most people who are not in the legal field, it is already an embedded concept in our daily life. The meaning is quite straightforward: "one is not allowed from making assertions that are contradictory to his or her prior position, ${ }^{1}$ although a seemingly fair and clear concept to understand, toeing the mark is not that simple, especially in the realm of scientific research.

As we know, we build our knowledge on existing knowledge; thus, conducting a series of studies is a process of approaching the truth - or at least what we believe to be the truth. Because a map is not provided for this expedition, some studies may lead people in the wrong way. Yet once other researchers point out this wrong direction, we - academia as a whole — simply return and take another direction. As a scientist, we all agree this correction process is normal and, most importantly, we seldom blame those who took the step to wrong way - as long as the research result was not fabricated. Maybe we carry on for a while, but soon camaraderie takes us back to our logical state of mind, reminding us that we are all human and "to err is human".

Yet what if the person who identified the wrong direction was me, myself? In other words, what if I recognize that my new study results are different from those of my past study? The above mentioned smooth correction mechanism may stop functioning, and we easily fall into a panic. This is the very moment when the logic of estoppels rolls in. We hesitate to say "maybe I took you in a wrong direction." Instead, in many cases, we torture the new data until the results are concordant with the previous study, creating a kind of confirmation bias. In extreme cases, new results are buried in a folder on our hard drive, the name of which is destined to be forgotten soon.

So, where did this modus operandi come from? We can come up with several scenarios. For a rookie researcher like a graduate student, one might consider these different results to be signaling a mistake. At that stage as a researcher, the person can easily fear looking incompetent or even a reprimand from his or her advisor. Then the young and poor soul summons estoppel. For a seasoned researcher, his or her pride or obsession with bravado might hinder the researcher from declaring the change in directions. When external funds are related and multiple stakeholders' expectations are mingled, especially with large, long-term research, the pressure to get new information aligned with existing information gets even bigger. At this level, almost a team level, the estoppels are observed.

Practically, estopping oneself seems the most convenient way-at least for an individual researcher. However, such behavior certainly and significantly slows down the improvement of science as a whole. Now our discussion of a legal word is reaching a level of philosophy, such as utilitarianism, ${ }^{3}$ but let us not get this route. We believe that estopping oneself is not helping improve our body of knowledge at all. As long as the new study was conducted under thorough guidance in a correct way, exercising an estoppels could do more harm to the scientific arena by preventing knowledge from being updated,
Volume 6 Issue 4 - 2017

\author{
Heon Jae Jeong,' Kyong Eun Lee,' Wui \\ Chiang Lee ${ }^{2}$ \\ 'Advisor, Joint Commission Taiwan, Taiwan \\ ${ }^{2}$ Department of Medical Affairs and Planning, Taipei Veterans \\ General Hospital \& National Yang-Ming University School of \\ Medicine, Taiwan
}

Correspondence: Wui Chiang Lee, Department of medica affairs and planning, Taipei veterans general hospital \& National Yang-Ming university school of medicine, Taipei, Taiwan, Tel +8862-28757/20, Email leewuichiang@gmail.com

Received: October 30, 2017 | Published: November 06, 2017

highlighting a serious missed opportunity to correct the direction much earlier.

Then, what can we do now? We believe any prudent researchers effectively understand a priori the importance of quickly updating knowledge. In addition, from time to time they feel fear of estoppels. After all, the choice of exercising estoppels is determined by weighing the merit and demerit with a scale that is calibrated largely by the atmosphere of academia. Thus, it is actually a cultural issue, which is the most difficult to change. ${ }^{4}$

This short editorial is not intended to provide solutions. We hope this serves as an official acknowledgement of such a phenomenon so we can discuss it more and eradicate it. As of now, no instrument exists to measure how often this estoppels-like behavior is conducted, but nobody can disavow that it happens. We all know it does.

It is time to exhume something lying deep inside your folder, waiting to be rejuvenated and contribute to make the world a better place. At the end of the day, the scientific arena can build a brave new world where such psychological pressure to update one's study results or methods do not exist.

\section{Acknowledgements}

None.

\section{Conflicts of interest}

The author declares that there are no conflicts of interest.

\section{References}

1. Gifis SH. Barron's law dictionary. Barron's. 2016.

2. Kohn LT, Corrigan JM, Donaldson MS. To err is human: building a safer health care system. USA:National Academies Press. 2000.

3. Sandel MJ. Liberalism and the limits of justice. USA:Cambridge University Press. 1998.

4. Jeong HJ, Pham JC, Kim M, et al. Major cultural-compatibility complex: Considerations on cross-cultural dissemination of patient safety programmes. BMJ Quality \& Safety. 2012;21(7):612-615. 